\title{
A short review on emotion processing: a lateralized network of neuronal networks
}

\author{
Nicola Palomero-Gallagher ${ }^{1,2,3}$ [D $\cdot$ Katrin Amunts ${ }^{1,2}$
}

Received: 1 March 2021 / Accepted: 21 June 2021 / Published online: 3 July 2021

(c) The Author(s) 2021

\begin{abstract}
Emotions are valenced mental responses and associated physiological reactions that occur spontaneously and automatically in response to internal or external stimuli, and can influence our behavior, and can themselves be modulated to a certain degree voluntarily or by external stimuli. They are subserved by large-scale integrated neuronal networks with epicenters in the amygdala and the hippocampus, and which overlap in the anterior cingulate cortex. Although emotion processing is accepted as being lateralized, the specific role of each hemisphere remains an issue of controversy, and two major hypotheses have been proposed. In the right-hemispheric dominance hypothesis, all emotions are thought to be processed in the right hemisphere, independent of their valence or of the emotional feeling being processed. In the valence lateralization hypothesis, the left is thought to be dominant for the processing of positively valenced stimuli, or of stimuli inducing approach behaviors, whereas negatively valenced stimuli, or stimuli inducing withdrawal behaviors, would be processed in the right hemisphere. More recent research points at the existence of multiple interrelated networks, each associated with the processing of a specific component of emotion generation, i.e., its generation, perception, and regulation. It has thus been proposed to move from hypotheses supporting an overall hemispheric specialization for emotion processing toward dynamic models incorporating multiple interrelated networks which do not necessarily share the same lateralization patterns.
\end{abstract}

Keywords Emotion $\cdot$ Brain networks $\cdot$ Limbic system $\cdot$ Asymmetry $\cdot$ Cingulate

\section{Introduction}

The brain is characterized by a conspicuous structural asymmetry which is accompanied by a functional lateralization, i.e., the hemispheres are differentially specialized for certain tasks, and to some extent can function independently of each other within the scope of these tasks. Although the focus of the present mini-review is on the human brain, it must be noted that lateralization of brain function in the emotional domain is not restricted to humans, but constitutes a widespread phenomenon found throughout the animal kingdom

Nicola Palomero-Gallagher

n.palomero-gallagher@fz-juelich.de

1 Institute of Neuroscience and Medicine (INM-1), Research Centre Jülich, 52425 Jülich, Germany

2 C. \& O. Vogt Institute for Brain Research, Heinrich-Heine-University, 40225 Düsseldorf, Germany

3 Department of Psychiatry, Psychotherapy, and Psychosomatics, Medical Faculty, RWTH, Aachen, Germany
(Güntürkün et al. 2020; Rogers and Vallortigara 2015; Vallortigara and Rogers 2020). Chimpanzees and several species of Old World monkeys display a right hemisphere dominance for both the perception and expression of emotions (Lindell 2013; Zhao et al. 2020). Giant pandas exhibit a leftwards lateralization in the processing of positive but not of negative stimuli (Liu et al. 2021). In dogs, positively and negatively valenced stimuli are associated with a higher amplitude of tail-wagging movements to the right and to the left side, respectively (Siniscalchi et al. 2013). Emotional reactions of bottlenose dolphins are stronger when negative stimuli are presented on their right than on their left side (Charles et al. 2021), and cuttlefish have a right eye preference for brightness matching associated with their camouflage abilities (Schnell et al. 2018). Finally, whereas honeybees show a bias to turn toward the scent of isoamyl acetate, an alarm pheromone, when it is presented on the right, and turn away from the source of this scent when presented on the left, they did not display an asymmetry in turning response to the odor of flowers on which they had been feeding prior to testing (Rogers and Vallortigara 2019). 
The most obvious structural lateralization in the human brain, the protrusions of the left occipital and the right frontal pole beyond their contralateral counterparts, is so prominent, that it is associated with so-called petalia-impressions on the inner surface of the skull (Hadziselimovic and Cus 1966a; Hadziselimovic and Ruzdic 1966b). Reports on functional lateralization date back as early as 1861, when Broca associated a lesion in the third convolution of the left frontal lobe with the patient's sudden loss of the ability to speak (Broca 1861a; b). Besides the richly documented asymmetry associated with speech production and language comprehension (Friederici and Gierhan 2013), lateralization has also been described for functions as varied motor control (Amunts et al. 1997; Sainburg et al. 2016; Sokolowska, 2021), visuospatial skills (Ciricugno et al. 2021; Vogel et al. 2003), and emotion processing (Demaree et al. 2005; Packheiser et al. 2021), to name only a few of many studies.

Structural asymmetry has been found in several regions that are involved in emotion processing, including the cingulate cortex, and related to behavior, psychopathology and illness, e.g., schizophrenia (Fujiwara et al. 2007). Another study suggested that differences in asymmetry of the anterior cingulate region may correspond with behavioral style, i.e., disposition to fear and anticipatory worry (Pujol et al. 2002), and lateralization has been discussed for emotion processing (Demaree et al. 2005).

Emotions are valenced mental responses to internal or external stimuli, which trigger visceromotor reflexes and modulate perception and cognition as well as physiological arousal, i.e., they induce feelings (Cabanac 2002; Ocklenburg and Güntürkün 2018). Thus, emotions enable adaptive behavior in response to specific events. Whereas Murphy and Zajonc (1993) postulated the existence of only two classes of emotion (i.e., positive and negative), Russell and Barrett (1999), Russell (2003), identified four "core affect" categories resulting from the blend of hedonic and arousal values (i.e., pleasure/good, displeasure/bad, activated/energized and sleepy/enervated), and Ekman (1992), Ekman et al. (1969) defined six discrete emotional states (i.e., basic emotions) based on the distinct facial expressions with which they are associated (i.e., anger, fear, sadness, enjoyment (or happiness), disgust and surprise), and each one of these basic emotions is associated with a specific neural network (Fusar-Poli et al. 2009b).

\section{Brain regions subserving emotion}

Emotion processing involves the coordinated activation of multiple large-scale neuronal networks encompassing both cortical and subcortical brain regions to enable identification of the emotional significance of stimuli as well as the induction and modulation of affective states and emotional behaviors.

Building on early models in which the limbic system was though to constitute the anatomic basis of emotions (MacLean 1970; Papez 1937; Yakovlev 1948, 1968), our understanding of the brain regions involved in the processing of this higher cognitive function has matured to the present concept of integrated pathways of distributed neural networks which are connected by the limbic system (Arciniegas 2013; Catani et al. 2013; Lindquist et al. 2012; Mesulam 2000; Pessoa 2018; Rolls 2015). Mesulam (2000) proposed that the amygdala and hippocampus are interconnected epicenters of two large-scale integrated pathways which are differentially involved in the various components of emotion and overlap in the anterior cingulate cortex.

\section{The amygdala-centered network}

The amygdala-centered network constitutes the neurobiological substrate for the integration of sensory input and emotional arousal to decode the significance of the stimulus for the organism, and includes the amygdala, areas of the olfactory, orbitofrontal, insular, anterior and midcingulate cortex as well as the ventral striatopallidum (Amaral et al. 1992; Catani et al. 2013; Geschwind 1965; Mesulam 2000).

The role of the amygdala is to assess a sensory stimulus on the basis of its intrinsic hedonic properties and possible association with other previously acquired primary reinforcers, as well as based on the organism's current motivational state to determine its valence and modulate its neural impact on the organism to induce an adequate emotional state (Mesulam 2000). Fear is probably the emotion category most often associated with the amygdala, and was first described in the seminal work by LeDoux (1994). Although the amygdala appears to play a more extensive role in negatively valenced emotions, it is also significantly involved in the processing of positively valenced stimuli (Cunningham and Kirkland 2014; Hamann et al. 2002; Wang et al. 2017), and depressed patients show higher amygdala responses to negative stimuli and lower amygdala responses to positive stimuli than do healthy controls (Groenewold et al. 2013). A meta-analytic functional connectivity-based parcellation of the amygdala revealed three clusters comparable in shape and relative position with the cytoarchitectonically identified laterobasal, centromedial, and superficial nuclei groups (Amunts et al. 2005; Bzdok et al. 2013). Functional profiling of the three clusters showed the "laterobasal cluster" to be associated with coordinating high-level sensory input, the "centromedial cluster" to mediate attentional, vegetative, and motor responses, and the "superficial cluster" to be involved in the processing of olfactory stimuli (Bzdok et al. 2013). 
The amygdala is able to integrate and process multimodal information, a primordial requisite for the modulation of higher cognitive functions such as emotional behavior, and this integrative function is subserved by its connectivity with numerous cortical and subcortical structures belonging to multiple functional systems. Furthermore, individual neurons in the amygdala not only respond to all types of unimodal sensory or viscerosensory stimuli, but also to multimodal sensory stimuli, to reward or punishment-related reinforcers, and to stimuli with a cognitive significance (Yilmazer-Hanke 2012). The primate amygdala is connected with primary/higher order unimodal areas belonging to all sensory systems, with multimodal areas of the orbitofrontal, anterior cingulate, insular, and temporal cortex, including the hippocampal complex (Aggleton et al. 1980, 2015; Aggleton and Saunders 2000; Amaral 1986; Amaral et al. 1992; Carmichael and Price 1995; Freese and Amaral 2005; Price 2003; Young et al. 1994). It is also connected with numerous subcortical structures, including the basal forebrain, thalamus, hypothalamus, periaqueductal central gray, and the peripeduncular nucleus (Aggleton et al. 1980; Price 2003). These connections are mostly reciprocal, and connectivity between the amygdala and unimodal sensory regions is organized in such a way that efferents arise from the higher order sensory areas, whereas the amygdala targets the primary or secondary sensory areas (Amaral et al. 1992; Turner et al. 1980). Visual input arises specifically from areas of the ventral visual stream, and gustatory and somatosensory information reaches the amygdala through a relay in the insula (Aggleton 1993; Mesulam and Mufson 1985).

The orbitofrontal cortex is involved in the integration of value-related olfactory and gustatory information with viscerosensory information (processed in the anterior insula), and in the transfer of this information to the pACC (Rolls 2019). The lateral orbitofrontal cortex showed a stronger functional connectivity with the gyral components of pACC area p24 (i.e., areas p24a and p24b), whereas medial orbitofrontal areas are more tightly associated with p24c (i.e., the sulcal component of area p24) and with p32 (PalomeroGallagher et al. 2019). The orbitofrontal cortex, together with subgenual cingulate area 25 (a key node of the cortical autonomic network; Gianaros et al. 2005; Kimmerly et al. 2005; Wong et al. 2007), also modulates autonomic and visceral functions in response to the valence of the stimulus, and does so via connections with the anterior insula, periaqueductal gray and hypothalamus (Critchley and Harrison 2013; Öngür and Price 2000; Palomero-Gallagher et al. 2015; Rempel-Clower and Barbas 1998).

The insula plays a major role in functional integration, and is thought to constitute a correlate of consciousness (Craig 2009). It is a structurally and functionally segregated brain region involved in olfactory, gustatory, sensorimotor and cognitive processes, including emotion processing
(Kurth et al. 2010; Mesulam and Mufson 1985). Interestingly, a meta-analysis of functional imaging studies revealed an overlap of activations related to the olfacto-gustatory, emotional and cognitive domains in the anterior-dorsal insula, which thus constitutes a key region in the human brain for the integration of olfaction, emotion and memory (Kurth et al. 2010). Furthermore, activation levels in the anterior insular cortex serve as correlates of the intensity of the experienced emotion, regardless of its valence (Zhu et al. 2019).

The amygdala targets the subgenual and pregenual parts of the anterior cingulate cortex (sACC and pACC, respectively) via the uncinate fasciculus, and cingulate regions are interconnected via the cingulate bundle (Dejerine 1895). The two ACC regions and the anterior midcingulate cortex (aMCC) monitor sensory stimuli, whereby ACC areas monitor emotional stimuli with respect to their pleasantness or unpleasantness (Oane et al. 2020; Palomero-Gallagher et al. 2015, 2019; Vogt and Miller 1983), and areas of the aMCC region play a crucial role in both the perception and anticipation of pain (Porro and Lui 2009; Vogt et al. 1996; Vogt and Sikes 2009b).

It is widely accepted that areas of the sACC subserve the processing of negatively valenced stimuli (Etkin et al. 2011; George et al. 1995; Karama et al. 2011; Liotti et al. 2000; Mechias et al. 2010; Smith et al. 2011). The processing of sadness and fear activates cytoarchitectonic areas s24 and s32, respectively (Palomero-Gallagher et al. 2015). Interestingly, pACC area p32 is associated with the domains of anxiety and fear, though these activations were elicited by tasks requiring the induction of emotions and theory of mind processes, and not by the experience of the emotion itself (Palomero-Gallagher et al. 2015). This association of area p32 with the subject's ability to experience empathy highlights the unique position of the cingulate cortex as a link between the emotional and memory domains, thus enabling cognitive influences on emotion (Palomero-Gallagher et al. 2015; Stevens et al. 2011). Notably, although some studies studying the neural substrate for the subjective feeling of happiness reported activations within ACC (e.g., Habel et al. 2005; Phillips et al. 1998), no meta-analytic approaches have been able to identify a significant association between the pACC (or any of its areas) and the processing of positively valenced emotions (Kirby and Robinson 2017; PalomeroGallagher et al. 2015; Phan et al. 2002; Torta and Cauda 2011; Vytal and Hamann 2010).

pACC receives gustatory and viscerosensory input from the orbitofrontal cortex, and is able to integrate visceral sensations via its reciprocal connections with the insula (Qadir et al. 2018; Taylor et al. 2009), and a recent cytoarchitectonically informed meta-analysis found the gyral components of pACC area p24 to be significantly associated with the behavioral domains of gustation and interoception 
(Palomero-Gallagher et al. 2019). These areas also co-activate with areas of the affective network (George et al. 1995; Lévesque et al. 2003), highlighting the importance of reward value in the generation of emotions (Glascher et al. 2012; Grabenhorst and Rolls 2011). Area p32 of pACC, and also area s24 of sACC, are involved in estimating the emotional valence of faces via visual input arising from areas of the ventral stream (Palomero-Gallagher et al. 2015, 2019). The pACC is also involved in conflict monitoring, and the sulcal component of area p24 is associated with action inhibition, and co-activates with components of the salience network (Palomero-Gallagher et al. 2019). Thus, the pACC integrates information from the dorsolateral prefrontal cortex concerning the selection and maintenance of options to current or proposed behaviors to provide the motivation to carry out selected behavior (Holroyd and Yeung 2012). Furthermore, it was shown that face-evoked responses in the anterior insula and anterior cingulate cortex contain information which is shaped by social interaction, and it was hypothesized that this provides a substrate of how social inclusion shapes future behavior and interaction, while the recognition of individual faces is supported by the visual cortex (Eger et al. 2013).

As part of both the amygdala- and the hippocampuscentered network, the ACC region is also able, either via its direct reciprocal connections with the rostral hippocampus, or in a relay through the thalamus, to modulate the consolidation and retrieval of memory (Aggleton 2012; Navawongse and Eichenbaum 2013; Xu and Sudhof 2013). Given that memories of emotionally valenced stimuli are easier to recollect than those of neutral ones, the ACC is thought to facilitate retrieval of related and competing memories by creating contextual representations of these experiences during the consolidation phase (Bian et al. 2019).

The aMCC receives input from ACC regions and also via the medial pain system and is thus in an ideal position to modulate avoidance behavior in response to noxius stimuli (Vogt 2005), whereby activations were found to be proportional to the degree of pain experienced (Derbyshire et al. 1998; Vogt et al. 1996). The aMCC is also activated during the processing of negatively valenced stimuli, and involved in the expression of fear responses (Pereira et al. 2010; Vogt et al. 2003). The MCC region projects to the supplementary areas, and the sulcal component of aMCC also contains a cingulate motor area (Morecraft and Tanji 2009; Vogt and Sikes 2009b), which projects directly to the facial motor nucleus and to portions of the spinal cord that control finger and hand movements. Thus, a brain network subserving emotion is able to directly generate and modulate facial, limb, or vocal reactions in response to a perceived stimulus. Furthermore, aMCC is thought to coordinate skeletomotor reflex responses in fear avoidance strategies (Vogt et al. 2003).
The ventral striatopallidum encompasses the ventral portions of the caudate nucleus, putamen and globus pallidus, as well as the nucleus accumbens and the olfactory tubercle (Mesulam 2000). It receives direct input from the amygdala, but is also connected with the orbitofrontal cortex and the $\mathrm{ACC}$, and is a central component of the reward circuit, and in the generation of emotional motor activity (Nieuwenhuys et al. 2008).

\section{The hippocampus-centered network}

The hippocampus-centered network mediates the integration of information processed by multiple large-scale brain networks involved in the different memory types to incorporate cognition into emotion processing. It includes the hippocampal complex, entorhinal and retrosplenial cortex (RSC), areas of the anterior (discussed above) and posterior cingulate cortex, as well as the thalamus (Mesulam 2000).

The hippocampal formation is a key structure in the consolidation and retrieval of declarative, spatial and emotional memory (Bird and Burgess 2008; Fanselow and Dong 2010; Strange et al. 2014), and the entorhinal cortex represents the nodal point in neocortico-hippocampal circuits (Insausti and Amaral 2008). The hippocampal formation consists of the hippocampus proper, with the Cornu Ammonis regions CA1-CA4 and the fascia dentata, and the subicular complex, with the prosubiculum, subiculum, presubiculum, and parasubiculum (Palomero-Gallagher et al. 2020). The hippocampus is situated at the top of a highly complex interconnected and hierarchically organized network participating in memory functions (for a comprehensive review see Aggleton 2012), and its reciprocal connections with the amygdala are of particular importance for affective and social learning (Insausti and Amaral 2012; Yilmazer-Hanke 2012).

The dorso-ventral axis of the rodent hippocampus, which is homolog to a posterior-to-anterior axis in primates, is structurally and functionally segregated (Fanselow and Dong 2010; Strange et al. 2014). The dorsal hippocampus is more densely connected with the RSC, mammillary bodies, and anterior thalamus, and is mainly involved in cognitive functions such as navigation and exploration (Fanselow and Dong 2010; Jones and Witter 2007; Moser et al. 1993; Risold and Swanson 1997; Strange et al. 2014; Witter 1993). The ventral hippocampus is more strongly connected to the amygdala, nucleus accumbens and hypothalamus, and is involved in motivated behavior and autonomic responses (Canteras and Swanson 1992; Fanselow and Dong 2010; Groenewegen et al. 1987; Henke 1990; Strange et al. 2014; van Groen and Wyss 1990). The primate hippocampus presents a comparable heterogeneity in structural connectivity, with a rostro-caudal decrease in connectivity with the amygdala, nucleus accumbens and prefrontal cortex, and a 
rostro-caudal increase in connectivity with the posterior cingulate cortex (PCC) and RSC (Aggleton 2012; Friedman et al. 2002; Fudge et al. 2012; Kobayashi and Amaral 2003, 2007).

In humans, the posterior hippocampus is activated during declarative and spatial memory tasks (Greicius et al. 2003; Maguire et al. 1997). Resting state functional connectivity analyses found the posterior hippocampus to be more highly connected to the RSC and lateral parietal cortex, i.e., areas involved in visuospatial cognition, whereas the anterior hippocampus was more strongly connected to the temporal, orbitofrontal and anterior cingulate cortex, i.e., areas associated with motivational behavior (Adnan et al. 2016; Vogel et al. 2020). There is also evidence of anatomical connectivity between the anterior hippocampus and the fusiform gyrus (Duvernoy 2005), a part of the visual system particularly involved in the identification of faces (Kanwisher and Yovel 2006), words (Cohen and Dehaene 2004) and places (Epstein et al. 1999; Epstein 2008), and single neurons in the human hippocampus have not only been found to respond differentially to faces and objects, but also to respond preferentially to specific emotional expressions (Fried et al. 1997). Interestingly, genes expressed in the posterior hippocampus correlate with cortical regions involved in memory processes, whereas gene expression in the anterior hippocampus correlates with regions involved in emotion (Vogel et al. 2020).

The hippocampal complex and entorhinal cortex are interconnected with the RSC and with PCC area 23, though connections are much denser with the former than with the latter region (Kobayashi and Amaral 2003). RSC is also densely interconnected with areas 24 and 23 of the ACC and PCC, respectively (Kobayashi and Amaral 2003, 2007). The RSC is reciprocally connected to dorsolateral prefrontal areas 9 and 46, and thus constitutes a link between the hippocampus and brain regions involved in executive functions (Kobayashi and Amaral 2003, 2007). It receives early visual input from areas v2 and v4 of the ventral stream and is also interconnected with inferior parietal area $7 \mathrm{a}$ (Kobayashi and Amaral 2003, 2007), which mediates visuomotor coordination (Rozzi et al. 2008). Reciprocal connections between the anterior thalamic nucleus and both the hippocampus and RSC facilitate the integration of visual and body-based orientation cues (Miller et al. 2014; Shine et al. 2016), the episodic retrieval of familiar places and objects (Sugiura et al. 2005), and provide an anatomical substrate for fear conditioning processes whereby the RSC is critically involved in tasks during which subjects must form appropriate associations among diverse cues and outcomes to perform optimally (Corcoran et al. 2016; Keene and Bucci 2008a, b). Thus, the RSC is in a position to modulate both the storage and retrieval of spatial and contextual information, in particular that related to fear.
The PCC is primarily involved in visuospatial, sensorimotor and long-term memory functions, and in the framework of emotion processing, plays a role in the assessment of the self-relevance of emotional events and stimuli (Vogt and Laureys 2009a). The PCC has reciprocal connections with sACC (Vogt and Pandya 1987), and is also targeted by the hippocampal complex and the RSC (Kobayashi and Amaral 2003, 2007). Furthermore, the PCC receives input from auditory association areas and has extensive connections with the inferior parietal cortex (Vogt and Pandya 1987) through which it receives input from areas belonging to the dorsal visual stream and involved in movement and spatial orientation (Kravitz et al. 2011; Ungerleider and Mishkin 1982). The convergence of visual and auditory stimuli together with information coded for valence in ACC enable the self-referential processing of stimuli and experiences.

\section{Lateralization of emotion processing}

As with language functions, our first inkling of a possible lateralization in the processing of emotions came from clinical observations of patients with left-brain lesions, since despite severe speech impairment, they retained traces of emotional language (Hughlings-Jackson 1878). Two main models of lateralization have been proposed, based on empirical support from studies in both patients and healthy subjects (Gainotti 2019a): the right-hemispheric dominance hypothesis and the valence lateralization hypothesis.

\section{Right-hemispheric dominance hypothesis}

The right-hemispheric dominance hypothesis proposes that the right half of the brain is dominant for the processing of all emotions, independent of their valence or of the emotional feeling being processed (Borod et al. 1998).

Patients with lesions in the right temporo-parietal region (i.e., Wernicke's region for language comprehension; Wernicke 1874) perform worse in tasks involving comprehension of the emotion expressed by affective speech than do patients with comparable left-hemispheric lesions (Heilman et al. 1975; Tucker et al. 1977). Right-hemispheric lesions affecting the fusiform face area (Kanwisher and Yovel 2006), impair the patient's ability to recognize the nature of the emotion conveyed by images of emotional faces (Adolphs et al. 1996). More widespread lesions in the right ventrolateral visual cortex also result in the inability to identify the valence or category of emotions depicted in in images of scenes (DeKosky et al. 1980). Unilateral focal excision of the right parieto-occipital cortex (Kolb and Taylor 1981), or electrical stimulation of right temporal visual-related cortex (Fried et al. 1982) also result in an impaired processing of facial expressions. Patients with right-hemispheric lesions 
are also unable to identify the valence or category of emotions depicted in in images of scenes (DeKosky et al. 1980). Interestingly, pictures of angry, happy or fearful faces, but not of neutral faces, elicited a right-lateralized activation of the amygdala when presented to a patient with bilateral damage to the primary visual cortex (Pegna et al. 2005). A recent meta-analysis revealed a significant correlation between the degree of emotional impairment in patients suffering from frontotemporal lobar degeneration and the degree of atrophy or hypometabolism of frontotemporal structures in the right hemisphere (Gainotti 2019b). A right-hemispheric dominance has been demonstrated for both the generation and the perception of emotional displays, since facial expressions on the left side of the face are more emotionally intense than those on the right side, and participants perceive emotional expressions to be more emotional when presented in the left than in the right visual field (Blom et al. 2020; Burt and Hausmann 2019; Lindell 2018; Prete et al. 2015; Sackeim and Gur 1978; Sackeim et al. 1978; Wyczesany et al. 2018).

Processing of emotion expression has also been found to be associated with lateralization of white matter pathways. The volumetric asymmetry of the uncinate fascicle, which connects components of the temporo-amygdala-orbitofrontal network and is larger in the right than in the left hemisphere, is positively correlated with lateralization of emotional expressivity of sad faces (Ioannucci et al. 2020). Furthermore, the rightward lateralization of the dorsal component of the superior longitudinal fascicle (i.e., SLF I) is negatively correlated with lateralization of emotional expressivity of happy faces (Ioannucci et al. 2020), and disruptions in the SLF are the most common white matter alteration in patients suffering from psychiatric emotional conditions (Jenkins et al. 2016).

\section{Valence lateralization hypothesis}

According to the valence lateralization hypothesis, both hemispheres are involved in the processing of emotion and emotional feelings, but in a manner dependent on the emotional valence of the information being processed, with a preference of the left hemisphere for positively valenced emotions and of the right one for negatively valenced ones (Davidson 1983). In a variant of this hypothesis, lateralization would be driven by motivational valence, with the left hemisphere being dominant for approach motivational tendencies and the right one for withdrawal ones (Demaree et al. 2005).

This hypothesis was formulated to explain the fact that pathological laughing conditions or indifference to one's own illness were frequently associated with damage to the right hemisphere, whereas pathological crying or the onset of depressive symptoms occurred mostly in patients with lesions to the left hemisphere (Bear 1983; Sackeim et al. 1982). Further support is provided by the observation that speech with a positively valenced emotional content resulted in an activation of the left amygdala of a long-term unresponsive comatose patient (Eickhoff et al. 2008), and positive visual stimuli elicit a left amygdalar activation in healthy subjects (Canli et al. 1998; Hamann et al. 2002; Lee et al. 2004). Interestingly, this normal left-lateralized amygdalar activity is often disturbed in patients with mental disorders (Allen et al. 2021; Baas et al. 2004). Divided visual field studies revealed that identification of positively valenced facial expressions or emotional words is faster and more accurate when these are presented in the right than in the left hemifield (i.e., when the stimulus is processed by the left vs. right hemisphere), and the opposite holds true for negatively valenced facial expressions or emotional words (Holtgraves and Felton 2011; Jonczyk 2015; Martin and Altarriba 2017; Reuter-Lorenz and Davidson 1981; Wyczesany et al. 2018). Analysis of alpha-band electroencephalographic activity in the frontal lobe revealed that stimuli designed to induce happiness elicit a greater cortical activity the left hemisphere, whereas stimuli designed to evoke negative emotions resulted in a greater cortical activity in the right hemisphere (Jones and Fox 1992; Zhao et al. 2018). A recent study addressing the ecological validity of the valence lateralization hypothesis by means of a mobile EEG recording system to monitor brain activity of romantic partners in their everyday environment also found emotional kisses to be associated with an increased asymmetry index in alphaband activity of the frontal lobe (Packheiser et al. 2021).

\section{Toward a more differentiated picture}

Lateralization associated with the processing of anger is best explained by the motivational variant of the valence hypothesis, since behaviourally this negatively valenced emotion is associated with the same kind of response as is happiness, i.e., with a drive toward the stimulus (Carver and Harmon-Jones 2009; Demaree et al. 2005). In line with the expected approach/withdrawal dominance, dichotic listening studies on the perception of sadness or anger through affective prosody revealed a greater involvement of the right hemisphere in the processing of sadness and of the left hemisphere in that of anger (Gadea et al. 2011). Likewise, viewing of angry faces resulted in a higher left prefrontal activity than that when neutral faces were presented (Schutter and Harmon-Jones 2013), as did anger induced experimentally by manipulated insult (Harmon-Jones and Sigelman 2001).

\section{Looking into the future: the need for hemispheric functional-equivalence hypotheses}

Function-location meta-analyses have been applied in an attempt to quantitatively integrate results from 
multiple studies belonging to a specific cognitive or emotional domain. E.g., in a meta-analysis of over 100 functional magnetic resonance imaging studies addressing the mechanisms underlying processing of emotional faces (Fusar-Poli et al. 2009a, b), the authors first tested regional activation differences for an effect of laterality independently from the valence of stimulus, and found the components of the emotion network to be bilaterally activated, thus providing no support for the right-hemispheric dominance hypothesis. The authors then searched for possible lateralization patterns based on both the motivational and the drive variants of the valence lateralization hypothesis. When testing for the emotional valence of the stimulus, a laterality was only to be induced by the processing of faces expressing negative emotions. However, contrary to what is predicted by the model, the activation was localized in the left hemisphere. Finally, when grouping stimuli according to their corresponding approach/withdrawal category, a left-lateralized activation was found in the inferior frontal gyrus during the processing of faces encoding approach emotions, and rightlateralized activations occurred in the medial frontal and middle frontal gyri during the processing of faces encoding withdrawal emotions. A meta-analysis addressing the neuroanatomical structures underpinning emotional experiences demonstrated that the basic emotions happiness, sadness, fear, anger and disgust are associated with distinct regional brain activation patterns (Vytal and Hamann 2010). A lateralization could only be associated with the processing of fear, since most prominent clusters are located in the right cerebellum and insula, as well as bilaterally in the amygdala. For each of the remaining basic emotions, largest activation clusters were found in both the left and right hemisphere (Vytal and Hamann 2010). Specifically, happiness is associated with activations in the right superior temporal gyrus and the left anterior cingulate cortex, sadness with clusters in the left caudate nucleus and medial frontal gyrus, as well as in the right inferior frontal gyrus. Anger is associated with activations of the left inferior frontal gyrus and right parahippocampal gyrus, and disgust with bilateral insular activations (Vytal and Hamann 2010). Finally, results of a multi-center study evaluating functional connectivity in resting state functional magnetic resonance imaging scans from over a thousand subjects also highlight the existence of both left- and right-dominant intrinsic connectivity hubs rather than that of a global hemispheric lateralization in the human brain (Nielsen et al. 2013). In this context, it has been postulated, that the right-hemispheric dominance and the valence lateralization models may reflect different aspects of emotion processing, thus highlighting the need to move away from the concept of an overall hemispheric specialization and to elaborate on the hypothesis that emotions are the result of activations in networks which are interrelated, but may have differential lateralization patterns (Fusar-Poli et al. 2009a; Killgore and Yurgelun-Todd 2007; Neumann et al. 2008).

Along such lines of argument, a hemispheric functionalequivalence hypothesis has recently been formulated to explain lateralization associated with the perception of emotional and neutral faces (Stankovic 2021). It is a dynamic model proposing the existence of an initial default setting in which the brain would be right-biased in emotional and neutral face perception, and this lateralization pattern would be maintained as long as environmental task demands remain low. However, since emotion perception should be viewed as a multi-layered phenomenon, increasing task demands would result in a redistribution of activity among the hemispheres as an adaptive mechanism to ensure continued accurate and prompt responses (Stankovic 2021). Since environmental requirements are known to modulate psychological modulators, this hypothesis would also explain how altered conditions such as acute stress could even result in a reversed lateralization. By proposing the functionalequivalence of both hemispheres, the model also accounts for intersubject variability in lateralization patterns, as it has been demonstrated that not all individuals display the asymmetry predispositions identified at the population level (Frasnelli and Vallortigara 2018).

Finally, a recent data-driven meta-analysis revealed that the perception, experience and expression of emotion are each subserved by a distinct large-scale network (Morawetz et al. 2020). Furthermore, three of these networks are composed of left-lateralized of bilaterally activated areas, whereas the fourth one contains left-lateralized, right-lateralized and bilateral activations. This is particularly interesting, given that the hemispheric functional-equivalence hypothesis of emotional face perception assumes an initial right-biased lateralization (Stankovic 2021), whereas the network that Morawetz et al. (2020) found to be associated with the perception of emotion (albeit not specifically in facial expressions) exhibits left-lateralized or bilateral activations. It thus appears necessary to not only abandon hypotheses supporting the concept of an overall hemispheric specialization, but to also move away from a global model of lateralization in emotion processing.

Acknowledgements This project has received funding from the European Union's Horizon 2020 Framework Programme for Research and Innovation under the Specific Grant Agreements 785907 (Human Brain Project SGA2) and 945539 (Human Brain Project SGA3).

Author contributions NP-G: conceptualization, writing-original draft, writing - review and editing, and funding acquisition. KA: writing - review and editing and funding acquisition.

Funding Open Access funding enabled and organized by Projekt DEAL. 


\section{Declarations}

Conflict of interest The authors have no conflicts to declare.

Open Access This article is licensed under a Creative Commons Attribution 4.0 International License, which permits use, sharing, adaptation, distribution and reproduction in any medium or format, as long as you give appropriate credit to the original author(s) and the source, provide a link to the Creative Commons licence, and indicate if changes were made. The images or other third party material in this article are included in the article's Creative Commons licence, unless indicated otherwise in a credit line to the material. If material is not included in the article's Creative Commons licence and your intended use is not permitted by statutory regulation or exceeds the permitted use, you will need to obtain permission directly from the copyright holder. To view a copy of this licence, visit http://creativecommons.org/licenses/by/4.0/.

\section{References}

Adnan A, Barnett A, Moayedi M, McCormick C, Cohn M, McAndrews MP (2016) Distinct hippocampal functional networks revealed by tractography-based parcellation. Brain Struct Funct 221:2999-3012

Adolphs R, Damasio H, Tranel D, Damasio AR (1996) Cortical systems for the recognition of emotion in facial expressions. J Neurosci 16:7678-7687

Aggleton JP (1993) The contribution of the amygdala to normal and abnormal emotional states. Trends Neurosci 16:328-333

Aggleton JP (2012) Multiple anatomical systems embedded within the primate medial temporal lobe: implications for hippocampal function. Neurosci Biobehav Rev 36:1579-1596

Aggleton JP, Saunders RC (2000) The amygdala—what's happened in the last decade? In: Aggleton JP (ed) The amygdala: a functional analysis. Oxford University Press, New York, pp 1-30

Aggleton JP, Burton MJ, Passingham RE (1980) Cortical and subcortical afferents to the amygdala of the rhesus monkey (Macaca mulatta). Brain Res 190:347-368

Aggleton JP, Wright NF, Rosene DL, Saunders RC (2015) Complementary patterns of direct amygdala and hippocampal projections to the macaque prefrontal cortex. Cereb Cortex 25:4351-4373

Allen HN, Bobnar HJ, Kolber BJ (2021) Left and right hemispheric lateralization of the amygdala in pain. Prog Neurobiol 196:101891

Amaral DG (1986) Amygdalahippocampal and amygdalacortical projections in the primate brain. In: Schwarcz R, Ben Ari Y (eds) Excitatory aminoacids and epilepsy. Plenum Press, New York, pp 3-17

Amaral DG, Price JL, Pitkänen A, Carmichael ST (1992) Anatomical organization of the primate amygdaloid complex. In: Aggleton JP (ed) The amygdala neurobiological aspects of emotion, memory and mental dysfunction. Wiley-Liss, New York, pp 1-66

Amunts K, Schlaug G, Jäncke L, Steinmetz H, Schleicher A, Dabringhaus A, Zilles K (1997) Motor cortex and hand motor skills: structural compliance in the human brain. Hum Brain Mapp $5: 206-215$

Amunts K, Kedo O, Kindler M, Pieperhoff P, Mohlberg H, Shah NJ, Habel U, Schneider F, Zilles K (2005) Cytoarchitectonic mapping of the human amygdala, hippocampal region and entorhinal cortex: intersubject variability and probability maps. Anat Embryol 210:343-352

Arciniegas DB (2013) Emotion. In: Arciniegas DB, Enderson A, Filley CM (eds) Behavioral neurology \& neuropsychiatry. Cambridge University Press, Cambridge, pp 266-298
Baas D, Aleman A, Kahn RS (2004) Lateralization of amygdala activation: a systematic review of functional neuroimaging studies. Brain Res Brain Res Rev 45:96-103

Bear DM (1983) Hemispheric specialization and the neurology of emotion. Arch Neurol 40:195-202

Bian XL, Qin C, Cai CY, Zhou Y, Tao Y, Lin YH, Wu HY, Chang L, Luo CX, Zhu DY (2019) Anterior cingulate cortex to ventral hippocampus circuit mediates contextual fear generalization. J Neurosci 39:5728-5739

Bird CM, Burgess N (2008) The hippocampus and memory: insights from spatial processing. Nat Rev Neurosci 9:182-194

Blom S, Aarts H, Semin GR (2020) Lateralization of facial emotion processing and facial mimicry. Laterality 25:259-274

Borod JC, Cicero BA, Obler LK, Welkowitz J, Erhan HM, Santschi C, Grunwald IS, Agosti RM, Whalen JR (1998) Right hemisphere emotional perception: evidence across multiple channels. Neuropsychology 12:446-458

Broca P (1861a) Perte de la parole, ramollissement chronique et destruction partielle du lobe antérieur du cerveau. Bull Soc Anthropol Paris 2:235-238-301-321

Broca P (1861b) Remarques sur le siège de la faculté du langage articulé, suivies d'une observation d'aphémie (perte de la parole). Bull Soci Anat 6:330-357

Burt DM, Hausmann M (2019) Hemispheric asymmetries in categorical facial expression perception. Emotion 19:584-592

Bzdok D, Laird AR, Zilles K, Fox PT, Eickhoff SB (2013) An investigation of the structural, connectional, and functional subspecialization in the human amygdala. Hum Brain Mapp $34: 3247-3266$

Cabanac M (2002) What is emotion? Behav Process 60:69-83

Canli T, Desmond JE, Zhao Z, Glover G, Gabrieli JD (1998) Hemispheric asymmetry for emotional stimuli detected with fMRI. NeuroReport 9:3233-3239

Canteras NS, Swanson LW (1992) Projections of the ventral subiculum to the amygdala, septum, and hypothalamus: a PHAL anterograde tract-tracing study in the rat. J Comp Neurol 324:180-194

Carmichael ST, Price JL (1995) Limbic connections of the orbital and medial prefrontal cortex in macaque monkeys. J Comp Neurol 363:615-641

Carver CS, Harmon-Jones E (2009) Anger is an approach-related affect: evidence and implications. Psychol Bull 135:183-204

Catani M, Dell'acqua F, Thiebaut de Schotten M (2013) A revised limbic system model for memory, emotion and behaviour. Neurosci Biobehav Rev 37:1724-1737

Charles A, Mercera B, Delfour F (2021) Bottlenose dolphins' (Tursiops Truncatus) visual and motor laterality depending on emotional contexts. Behav Processes 187:104374

Ciricugno A, Bartlett ML, Gwinn OS, Carragher DJ, Nicholls MER (2021) The effect of cognitive load on horizontal and vertical spatial asymmetries. Laterality. https://doi.org/10.1080/13576 50X.2021.1920972

Cohen L, Dehaene S (2004) Specialization within the ventral stream: the case for the visual word form area. Neuroimage 22:466-476

Corcoran KA, Frick BJ, Radulovic J, Kay LM (2016) Analysis of coherent activity between retrosplenial cortex, hippocampus, thalamus, and anterior cingulate cortex during retrieval of recent and remote context fear memory. Neurobiol Learn Mem 127:93-101

Craig AD (2009) How do you feel-now? The anterior insula and human awareness. Nat Rev Neurosci 10:59-70

Critchley HD, Harrison NA (2013) Visceral influences on brain and behavior. Neuron 77:624-638

Cunningham WA, Kirkland T (2014) The joyful, yet balanced, amygdala: moderated responses to positive but not negative stimuli in trait happiness. Soc Cogn Affect Neurosci 9:760-766 
Davidson RJ (1983) Hemispheric specialization for cognition and affect. In: Gale A, Edwards J (eds) Physiological correlates of human behavior. Academic Press, London, pp 203-216

Dejerine J (1895) Anatomie des Centres Nerveux. Rueff et Cie, Paris

DeKosky ST, Heilman KM, Bowers D, Valenstein E (1980) Recognition and discrimination of emotional faces and pictures. Brain Lang 9:206-214

Demaree HA, Everhart DE, Youngstrom EA, Harrison DW (2005) Brain lateralization of emotional processing: historical roots and a future incorporating "dominance." Behav Cogn Neurosci Rev 4:3-20

Derbyshire SW, Vogt BA, Jones AK (1998) Pain and Stroop interference tasks activate separate processing modules in anterior cingulate cortex. Exp Brain Res 118:52-60

Duvernoy HM (2005) The human hippocampus. Functional anatomy, vascularization and serial sections with MRI. Springer, Berlin, Heidelberg, New York

Eger E, Moretti L, Dehaene S, Sirigu A (2013) Decoding the representation of learned social roles in the human brain. Cortex 49:2484-2493

Eickhoff SB, Dafotakis M, Grefkes C, Stocker T, Shah NJ, Schnitzler A, Zilles K, Siebler M (2008) fMRI reveals cognitive and emotional processing in a long-term comatose patient. Exp Neurol 214:240-246

Ekman P (1992) An argument for basic emotions. Cogn Emot 6:169-200

Ekman P, Sorenson ER, Friesen WV (1969) Pan-cultural elements in facial displays of emotion. Science 164:86-88

Epstein RA (2008) Parahippocampal and retrosplenial contributions to human spatial navigation. Trends Cogn Sci 12:388-396

Epstein R, Harris A, Stanley D, Kanwisher N (1999) The parahippocampal place area: recognition, navigation, or encoding? Neuron 23:115-125

Etkin A, Egner T, Kalisch R (2011) Emotional processing in anterior cingulate and medial prefrontal cortex. Trends Cogn Sci 15:85-93

Fanselow MS, Dong HW (2010) Are the dorsal and ventral hippocampus functionally distinct structures? Neuron 65:7-19

Frasnelli E, Vallortigara G (2018) Individual-level and population-level lateralization: two sides of the same coin. Symmetry 10(12):739

Freese JL, Amaral DG (2005) The organization of projections from the amygdala to visual cortical areas TE and V1 in the macaque monkey. J Comp Neurol 486:295-317

Fried I, Mateer C, Ojemann G, Wohns R, Fedio P (1982) Organization of visuospatial functions in human cortex. Evidence from Electrical Stimulation Brain 105:349-371

Fried I, MacDonald KA, Wilson CL (1997) Single neuron activity in human hippocampus and amygdala during recognition of faces and objects. Neuron 18:753-765

Friederici AD, Gierhan SM (2013) The language network. Curr Opin Neurobiol 23:250-254

Friedman DP, Aggleton JP, Saunders RC (2002) Comparison of hippocampal, amygdala, and perirhinal projections to the nucleus accumbens: combined anterograde and retrograde tracing study in the Macaque brain. J Comp Neurol 450:345-365

Fudge JL, deCampo DM, Becoats KT (2012) Revisiting the hippocampal-amygdala pathway in primates: association with immatureappearing neurons. Neuroscience 212:104-119

Fujiwara H, Hirao K, Namiki C, Yamada M, Shimizu M, Fukuyama H, Hayashi T, Murai T (2007) Anterior cingulate pathology and social cognition in schizophrenia: a study of gray matter, white matter and sulcal morphometry. Neuroimage 36:1236-1245

Fusar-Poli P, Placentino A, Carletti F, Allen P, Landi P, Abbamonte M, Barale F, Perez J, McGuire P, Politi PL (2009a) Laterality effect on emotional faces processing: ALE meta-analysis of evidence. Neurosci Lett 452:262-267
Fusar-Poli P, Placentino A, Carletti F, Landi P, Allen P, Surguladze S, Benedetti F, Abbamonte M, Gasparotti R, Barale F et al (2009b) Functional atlas of emotional faces processing: a voxel-based meta-analysis of 105 functional magnetic resonance imaging studies. J Psychiatry Neurosci 34:418-432

Gadea M, Espert R, Salvador A, Marti-Bonmati L (2011) The sad, the angry, and the asymmetrical brain: dichotic listening studies of negative affect and depression. Brain Cogn 76:294-299

Gainotti G (2019a) A historical review of investigations on laterality of emotions in the human brain. J Hist Neurosci 28:23-41

Gainotti G (2019b) The Role of the Right Hemisphere in Emotional and Behavioral Disorders of Patients With Frontotemporal Lobar Degeneration: An Updated Review. Front Aging Neurosci 11:55

George MS, Ketter TA, Parekh PI, Horwitz B, Herscovitch P, Post RM (1995) Brain activity during transient sadness and happiness in healthy women. Am J Psychiatry 152:341-351

Geschwind N (1965) Disconnexion syndromes in animals and man. I Brain 88:237-294

Gianaros PJ, Derbyshire SW, May JC, Siegle GJ, Gamalo MA, Jennings JR (2005) Anterior cingulate activity correlates with blood pressure during stress. Psychophysiology 42:627-635

Glascher J, Adolphs R, Damasio H, Bechara A, Rudrauf D, Calamia M, Paul LK, Tranel D (2012) Lesion mapping of cognitive control and value-based decision making in the prefrontal cortex. Proc Natl Acad Sci U S A 109:14681-14686

Grabenhorst F, Rolls ET (2011) Value, pleasure and choice in the ventral prefrontal cortex. Trends Cogn Sci 15:56-67

Greicius MD, Krasnow B, Boyett-Anderson JM, Eliez S, Schatzberg AF, Reiss AL, Menon V (2003) Regional analysis of hippocampal activation during memory encoding and retrieval: fMRI study. Hippocampus 13:164-174

Groenewegen HJ, Vermeulen-Van der Zee E, te Kortschot A, Witter MP (1987) Organization of the projections from the subiculum to the ventral striatum in the rat. A study using anterograde transport of Phaseolus vulgaris leucoagglutinin. Neuroscience 23:103-120

Groenewold NA, Opmeer EM, de Jonge P, Aleman A, Costafreda SG (2013) Emotional valence modulates brain functional abnormalities in depression: evidence from a meta-analysis of fMRI studies. Neurosci Biobehav Rev 37:152-163

Güntürkün O, Strockens F, Ocklenburg S (2020) Brain Lateralization: A Comparative Perspective. Physiol Rev 100:1019-1063

Habel U, Klein M, Kellermann T, Shah NJ, Schneider F (2005) Same or different? Neural correlates of happy and sad mood in healthy males. Neuroimage 26:206-214

Hadziselimovic H, Cus M (1966a) The appearance of internal structures of the brain in relation to configuration of the human skull. Acta Anat (basel) 63:289-299

Hadziselimovic H, Ruzdic N (1966b) Appearance of the base of the brain in relation to the configuration of human skull. Acta Anat (basel) 65:146-156

Hamann SB, Ely TD, Hoffman JM, Kilts CD (2002) Ecstasy and agony: activation of the human amygdala in positive and negative emotion. Psychol Sci 13:135-141

Harmon-Jones E, Sigelman J (2001) State anger and prefrontal brain activity: evidence that insult-related relative left-prefrontal activation is associated with experienced anger and aggression. J Pers Soc Psychol 80:797-803

Heilman KM, Scholes R, Watson RT (1975) Auditory affective agnosia. Disturbed comprehension of affective speech. J Neurol Neurosurg Psychiatry 38:69-72

Henke PG (1990) Hippocampal pathway to the amygdala and stress ulcer development. Brain Res Bull 25:691-695

Holroyd CB, Yeung N (2012) Motivation of extended behaviors by anterior cingulate cortex. Trends Cogn Sci 16:122-128 
Holtgraves T, Felton A (2011) Hemispheric asymmetry in the processing of negative and positive words: a divided field study. Cogn Emot 25:691-699

Hughlings-Jackson J (1878) Ôn affections of speech from disease of the brain. Brain 1:304-330

Insausti R, Amaral DG (2008) Entorhinal cortex of the monkey: IV. Topographical and laminar organization of cortical afferents. J Comp Neurol 509:608-641

Insausti R, Amaral DG (2012) Hippocampal formation. In: Mai JK, Paxinos G (eds) The human nervous system. Academic Press, Amsterdam, pp 896-942

Ioannucci S, George N, Friedrich P, Cerliani L, Thiebaut de Schotten M (2020) White matter correlates of hemi-face dominance in happy and sad expression. Brain Struct Funct 225:1379-1388

Jenkins LM, Barba A, Campbell M, Lamar M, Shankman SA, Leow AD, Ajilore O, Langenecker SA (2016) Shared white matter alterations across emotional disorders: A voxel-based meta-analysis of fractional anisotropy. Neuroimage Clin 12:1022-1034

Jonczyk R (2015) Hemispheric asymmetry of emotion words in a non-native mind: a divided visual field study. Laterality 20:326-347

Jones NA, Fox NA (1992) Electroencephalogram asymmetry during emotionally evocative films and its relation to positive and negative affectivity. Brain Cogn 20:280-299

Jones BF, Witter MP (2007) Cingulate cortex projections to the parahippocampal region and hippocampal formation in the rat. Hippocampus 17:957-976

Kanwisher N, Yovel G (2006) The fusiform face area: a cortical region specialized for the perception of faces. Philos Trans R Soc Lond B Biol Sci 361:2109-2128

Karama S, Armony J, Beauregard M (2011) Film excerpts shown to specifically elicit various affects lead to overlapping activation foci in a large set of symmetrical brain regions in males. PLoS ONE 6:e22343

Keene CS, Bucci DJ (2008a) Involvement of the retrosplenial cortex in processing multiple conditioned stimuli. Behav Neurosci 122:651-658

Keene CS, Bucci DJ (2008b) Neurotoxic lesions of retrosplenial cortex disrupt signaled and unsignaled contextual fear conditioning. Behav Neurosci 122:1070-1077

Killgore WD, Yurgelun-Todd DA (2007) The right-hemisphere and valence hypotheses: could they both be right (and sometimes left)? Soc Cogn Affect Neurosci 2:240-250

Kimmerly DS, O'Leary DD, Menon RS, Gati JS, Shoemaker JK (2005) Cortical regions associated with autonomic cardiovascular regulation during lower body negative pressure in humans. J Physiol 569:331-345

Kirby LAJ, Robinson JL (2017) Affective mapping: an activation likelihood estimation (ALE) meta-analysis. Brain Cogn 118:137-148

Kobayashi Y, Amaral DG (2003) Macaque monkey retrosplenial cortex: II. Cortical Afferents J Comp Neurol 466:48-79

Kobayashi Y, Amaral DG (2007) Macaque monkey retrosplenial cortex: III. Cortical Efferents J Comp Neurol 502:810-833

Kolb B, Taylor L (1981) Affective behavior in patients with localized cortical excisions: role of lesion site and side. Science 214:89-91

Kravitz DJ, Saleem KS, Baker CI, Mishkin M (2011) A new neural framework for visuospatial processing. Nat Rev Neurosci 12:217-230

Kurth F, Zilles K, Fox PT, Laird AR, Eickhoff SB (2010) A link between the systems: functional differentiation and integration within the human insula revealed by meta-analysis. Brain Struct Funct 214:519-534

LeDoux JE (1994) Emotion, memory and the brain. Sci Am 270:50-57
Lee GP, Meador KJ, Loring DW, Allison JD, Brown WS, Paul LK, Pillai JJ, Lavin TB (2004) Neural substrates of emotion as revealed by functional magnetic resonance imaging. Cogn Behav Neurol 17:9-17

Lévesque J, Joanette Y, Mensour B, Beaudoin G, Leroux JM, Bourgouin P, Beauregard M (2003) Neural correlates of sad feelings in healthy girls. Neuroscience 121:545-551

Lindell AK (2013) Continuities in emotion lateralization in human and non-human primates. Front Hum Neurosci 7:464

Lindell A (2018) Lateralization of the expression of facial emotion in humans. In: Forrester GS, Hopkins WD, Hudry K, Lindell A (eds) Cerebral lateralization and cognition: Evolutionary and developmental investigations of behavioral biases. Elsevier, Cambridge, pp 249-270

Lindquist KA, Wager TD, Kober H, Bliss-Moreau E, Barrett LF (2012) The brain basis of emotion: a meta-analytic review. Behav Brain Sci 35:121-143

Liotti M, Mayberg HS, Brannan SK, McGinnis S, Jerabek P, Fox PT (2000) Differential limbic-cortical correlates of sadness and anxiety in healthy subjects: implications for affective disorders. Biol Psychiatry 48:30-42

Liu H, Tang Y, Ni Y, Fang G (2021) Laterality in responses to acoustic stimuli in giant pandas. Animals (basel) 11:774

MacLean PD (1970) The triune brain, emotion and scientific basis. In: Schmitt FO (ed) The neurosciences: second study program. Rockefeller University Press, New York, pp 336-349

Maguire EA, Frackowiak RSJ, Frith CD (1997) Recalling routes around london: activation of the right hippocampus in taxi drivers. J Neurosci 17:7103-7110

Martin JM, Altarriba J (2017) Effects of valence on hemispheric specialization for emotion word processing. Lang Speech 60:597-613

Mechias ML, Etkin A, Kalisch R (2010) A meta-analysis of instructed fear studies: implications for conscious appraisal of threat. Neuroimage 49:1760-1768

Mesulam MM (2000) Behavioral neuroanatomy: large-scale networks, association cortex, frontal syndromes, the limbic system, and hemispheric specializations. In: Mesulam MM (ed) Principles of behavioral and cognitive neurology. Oxford University Press, Oxford, pp 1-120

Mesulam MM, Mufson EJ (1985) The insula of Reil in man and monkey Architectonics, connectivity and function. In: Peters A, Jones EG (eds) Cereb cortex. Plenum, New York, pp 179-226

Miller AM, Vedder LC, Law LM, Smith DM (2014) Cues, context, and long-term memory: the role of the retrosplenial cortex in spatial cognition. Front Hum Neurosci 8:586

Morawetz C, Riedel MC, Salo T, Berboth S, Eickhoff SB, Laird AR, Kohn N (2020) Multiple large-scale neural networks underlying emotion regulation. Neurosci Biobehav Rev 116:382-395

Morecraft RJ, Tanji J (2009) Cingulofrontal interactions and the cingulate motor areas. In: Vogt BA (ed) Cingulate neurobiology and disease. Oxford University Press, Oxford, pp 113-144

Moser E, Moser MB, Andersen P (1993) Spatial learning impairment parallels the magnitude of dorsal hippocampal lesions, but is hardly present following ventral lesions. J Neurosci 13:3916-3925

Murphy ST, Zajonc RB (1993) Affect, cognition, and awareness: affective priming with optimal and suboptimal stimulus exposures. J Pers Soc Psychol 64:723-739

Navawongse R, Eichenbaum H (2013) Distinct pathways for rule-based retrieval and spatial mapping of memory representations in hippocampal neurons. J Neurosci 33:1002-1013

Neumann J, von Cramon DY, Lohmann G (2008) Model-based clustering of meta-analytic functional imaging data. Hum Brain Mapp 29:177-192 
Nielsen JA, Zielinski BA, Ferguson MA, Lainhart JE, Anderson JS (2013) An evaluation of the left-brain vs. right-brain hypothesis with resting state functional connectivity magnetic resonance imaging. PLoS ONE 8:e71275

Nieuwenhuys R, Voogd J, van Huijzen C (2008) The Human Central Nervous System, 4th edn. Springer, Berlin

Oane I, Barborica A, Chetan F, Donos C, Maliia MD, Arbune AA, Daneasa A, Pistol C, Nica AE, Bajenaru OA et al (2020) Cingulate cortex function and multi-modal connectivity mapped using intracranial stimulation. Neuroimage 220:117059

Ocklenburg S, Güntürkün O (2018) Hemispheric asymmetries in emotion processing. In: Ocklenburg S, Güntürkün O (eds) The lateralized brain: the neuroscience and evolution of hemispheric asymmetries. Academic Press, pp 213-238

Öngür D, Price JL (2000) The organization of networks within the orbital and medial prefrontal cortex of rats, monkeys and humans. Cereb Cortex 10:206-219

Packheiser J, Berretz G, Rook N, Bahr C, Schockenhoff L, Gunturkun O, Ocklenburg S (2021) Investigating real-life emotions in romantic couples: a mobile EEG study. Sci Rep 11:1142

Palomero-Gallagher N, Eickhoff SB, Hoffstaedter F, Schleicher A, Mohlberg H, Vogt BA, Amunts K, Zilles K (2015) Functional organization of human subgenual cortical areas: relationship between architectonical segregation and connectional heterogeneity. Neuroimage 115:177-190

Palomero-Gallagher N, Hoffstaedter F, Mohlberg H, Eickhoff SB, Amunts K, Zilles K (2019) Human pregenual anterior cingulate cortex: structural, functional, and connectional heterogeneity. Cereb Cortex 29:2552-2574

Palomero-Gallagher N, Kedo O, Mohlberg H, Zilles K, Amunts K (2020) Multimodal mapping and analysis of the cyto- and receptorarchitecture of the human hippocampus. Brain Struct Funct 225:881-907

Papez JW (1937) A proposed mechanism of emotion. Arch Neurol Psychiatr 38:725-733

Pegna AJ, Khateb A, Lazeyras F, Seghier ML (2005) Discriminating emotional faces without primary visual cortices involves the right amygdala. Nat Neurosci 8:24-25

Pereira MG, de Oliveira L, Erthal FS, Joffily M, Mocaiber IF, Volchan E, Pessoa L (2010) Emotion affects action: Midcingulate cortex as a pivotal node of interaction between negative emotion and motor signals. Cogn Affect Behav Neurosci 10:94-106

Pessoa L (2018) Understanding emotion with brain networks. Curr Opin Behav Sci 19:19-25

Phan KL, Wager T, Taylor SF, Liberzon I (2002) Functional neuroanatomy of emotion: a meta-analysis of emotion activation studies in PET and fMRI. Neuroimage 16:331-348

Phillips ML, Bullmore ET, Howard R, Woodruff PW, Wright IC, Williams SC, Simmons A, Andrew C, Brammer M, David AS (1998) Investigation of facial recognition memory and happy and sad facial expression perception: an fMRI study. Psychiatry Res 83:127-138

Porro CA, lui F (2009) Pain anticipation in the cingulate gyrus. In: Vogt BA (ed) Cingulate neurobiology and disease. Oxford University Press, Oxford, pp 365-379

Prete G, Capotosto P, Zappasodi F, Laeng B, Tommasi L (2015) The cerebral correlates of subliminal emotions: an eleoencephalographic study with emotional hybrid faces. Eur J Neurosci 42:2952-2962

Price JL (2003) Comparative aspects of amygdala connectivity. Ann N Y Acad Sci 985:50-58

Pujol J, Lopez A, Deus J, Cardoner N, Vallejo J, Capdevila A, Paus T (2002) Anatomical variability of the anterior cingulate gyrus and basic dimensions of human personality. Neuroimage 15:847-855

Qadir H, Krimmel SR, Mu C, Poulopoulos A, Seminowicz DA, Mathur BN (2018) Structural connectivity of the anterior cingulate cortex, claustrum, and the anterior insula of the mouse. Front Neuroanat 12:100

Rempel-Clower NL, Barbas H (1998) Topographic organization of connections between the hypothalamus and prefrontal cortex in the rhesus monkey. J Comp Neurol 398:393-419

Reuter-Lorenz P, Davidson RJ (1981) Differential contributions of the two cerebral hemispheres to the perception of happy and sad faces. Neuropsychologia 19:609-613

Risold PY, Swanson LW (1997) Connections of the rat lateral septal complex. Brain Res Brain Res Rev 24:115-195

Rogers LJ, Vallortigara G (2015) When and why did brains break symmetry? Symmetry 7:2181-2194

Rogers LJ, Vallortigara G (2019) Complementary specializations of the left and right sides of the honeybee brain. Front Psychol 10:280

Rolls ET (2015) Limbic systems for emotion and for memory, but no single limbic system. Cortex 62:119-157

Rolls ET (2019) The cingulate cortex and limbic systems for action, emotion, and memory. Handb Clin Neurol 166:23-37

Rozzi S, Ferrari PF, Bonini L, Rizzolatti G, Fogassi L (2008) Functional organization of inferior parietal lobule convexity in the macaque monkey: electrophysiological characterization of motor, sensory and mirror responses and their correlation with cytoarchitectonic areas. Eur J Neurosci 28:1569-1588

Russell JA (2003) Core affect and the psychological construction of emotion. Psychol Rev 110:145-172

Russell JA, Barrett LF (1999) Core affect, prototypical emotional episodes, and other things called emotion: dissecting the elephant. J Pers Soc Psychol 76:805-819

Sackeim HA, Gur RC (1978) Lateral asymmetry in intensity of emotional expression. Neuropsychologia 16:473-481

Sackeim HA, Gur RC, Saucy MC (1978) Emotions are expressed more intensely on the left side of the face. Science 202:434-436

Sackeim HA, Greenberg MS, Weiman AL, Gur RC, Hungerbuhler JP, Geschwind N (1982) Hemispheric asymmetry in the expression of positive and negative emotions. Neurolog Evid Arch Neurol 39:210-218

Sainburg RL, Schaefer SY, Yadav V (2016) Lateralized motor control processes determine asymmetry of interlimb transfer. Neuroscience 334:26-38

Schnell AK, Bellanger C, Vallortigara G, Jozet-Alves C (2018) Visual asymmetries in cuttlefish during brightness matching for camouflage. Curr Biol 28:R925-R926

Schutter DJ, Harmon-Jones E (2013) The corpus callosum: a commissural road to anger and aggression. Neurosci Biobehav Rev 37:2481-2488

Shine JP, Valdes-Herrera JP, Hegarty M, Wolbers T (2016) The human retrosplenial cortex and thalamus code head direction in a global reference frame. J Neurosci 36:6371-6381

Siniscalchi M, Lusito R, Vallortigara G, Quaranta A (2013) Seeing leftor right-asymmetric tail wagging produces different emotional responses in dogs. Curr Biol 23:2279-2282

Smith R, Fadok RA, Purcell M, Liu S, Stonnington C, Spetzler RF, Baxter LC (2011) Localizing sadness activation within the subgenual cingulate in individuals: a novel functional MRI paradigm for detecting individual differences in the neural circuitry underlying depression. Brain Imaging Behav 5:229-239

Sokolowska B (2021) A novel virtual reality approach for functional lateralization in healthy adults. Brain Res 1766:147537

Stankovic M (2021) A conceptual critique of brain lateralization models in emotional face perception: Toward a hemispheric functional-equivalence (HFE) model. Int J Psychophysiol 160:57-70

Stevens FL, Hurley RA, Taber KH (2011) Anterior cingulate cortex: unique role in cognition and emotion. J Neuropsychiatry Clin Neurosci 23:121-125 
Strange BA, Witter MP, Lein ES, Moser EI (2014) Functional organization of the hippocampal longitudinal axis. Nat Rev Neurosci 15:655-669

Sugiura M, Shah NJ, Zilles K, Fink GR (2005) Cortical representations of personally familiar objects and places: functional organization of the human posterior cingulate cortex. J Cogn Neurosci 17:183-198

Taylor KS, Seminowicz DA, Davis KD (2009) Two systems of resting state connectivity between the insula and cingulate cortex. Hum Brain Mapp 30:2731-2745

Torta DM, Cauda F (2011) Different functions in the cingulate cortex, a meta-analytic connectivity modeling study. Neuroimage 56:2157-2172

Tucker DM, Watson RT, Heilman KM (1977) Discrimination and evocation of affectively intoned speech in patients with right parietal disease. Neurology 27:947-950

Turner BH, Mishkin M, Knapp M (1980) Organization of the amygdalopetal projections from modality-specific cortical association areas in the monkey. J Comp Neurol 191:515-543

Ungerleider LG, Mishkin M (1982) Two cortical visual systems. In: Ingle DJ, Goodale MA, Mansfield RJW (eds) Analysis of visual behavior. MIT Press, Cambridge, pp 549-586

Vallortigara G, Rogers LJ (2020) A function for the bicameral mind. Cortex 124:274-285

van Groen T, Wyss JM (1990) Extrinsic projections from area CA1 of the rat hippocampus: olfactory, cortical, subcortical, and bilateral hippocampal formation projections. J Comp Neurol 302:515-528

Vogel JJ, Bowers CA, Vogel DS (2003) Cerebral lateralization of spatial abilities: a meta-analysis. Brain Cogn 52:197-204

Vogel JW, La Joie R, Grothe MJ, Diaz-Papkovich A, Doyle A, Vachon-Presseau E, Lepage C, Vos de Wael R, Thomas RA, Iturria-Medina $\mathrm{Y}$ et al (2020) A molecular gradient along the longitudinal axis of the human hippocampus informs large-scale behavioral systems. Nat Commun 11:960

Vogt BA (2005) Pain and emotion interactions in subregions of the cingulate gyrus. Nat Rev Neurosci 6:533-544

Vogt BA, Miller MW (1983) Cortical connections between rat cingulate cortex and visual, motor, and postsubicular cortices. J Comp Neurol 216:192-210

Vogt BA, Pandya DN (1987) Cingulate cortex of the rhesus monkey: II. Cortical Afferents J Comp Neurol 262:271-289

Vogt BA, Laureys S (2009a) The primate posterior cingulate gyrus: connections, sensorimotor orientation, gateway to limbic processing. In: Vogt BA (ed) Cingulate neurobiology and disease. Oxford University Press, Oxford, pp 275-308

Vogt BA, Sikes RW (2009b) Cingulate nociceptive circuitry and roles in pain processing: the cingulate premotor pain model. In: Vogt BA (ed) Cingulate neurobiology and disease. Oxford University Press, Oxford, pp 311-338

Vogt BA, Derbyshire S, Jones AK (1996) Pain processing in four regions of human cingulate cortex localized with co-registered PET and MR imaging. Eur J Neurosci 8:1461-1473
Vogt BA, Berger GR, Derbyshire SWG (2003) Structural and functional dichotomy of human midcingulate cortex. Eur J Neurosci 18:3134-3144

Vytal K, Hamann S (2010) Neuroimaging support for discrete neural correlates of basic emotions: a voxel-based meta-analysis. J Cogn Neurosci 22:2864-2885

Wang S, Yu R, Tyszka JM, Zhen S, Kovach C, Sun S, Huang Y, Hurlemann R, Ross IB, Chung JM et al (2017) The human amygdala parametrically encodes the intensity of specific facial emotions and their categorical ambiguity. Nat Commun 8:14821

Wernicke C (1874) Der aphasische Symptomencomplex Eine psychologische Studie auf anatomischer Basis. M. Cohn \& Weigert, Breslau

Witter MP (1993) Organization of the entorhinal-hippocampal system: a review of current anatomical data. Hippocampus 3:33-44

Wong SW, Masse N, Kimmerly DS, Menon RS, Shoemaker JK (2007) Ventral medial prefrontal cortex and cardiovagal control in conscious humans. Neuroimage 35:698-708

Wyczesany M, Capotosto P, Zappasodi F, Prete G (2018) Hemispheric asymmetries and emotions: evidence from effective connectivity. Neuropsychologia 121:98-105

Xu W, Sudhof TC (2013) A neural circuit for memory specificity and generalization. Science 339:1290-1295

Yakovlev PI (1948) Motility, behavior and the brain; stereodynamic organization and neural coordinates of behavior. J Nerv Ment Dis 107:313-335

Yakovlev PI (1968) Telencephalon "impar", "semipar" and "totopar". (Morphogenetic, tectogenetic and architectonic definitions). Int J Neurol 6:245-265

Yilmazer-Hanke DM (2012) Amygdala. In: Mai JK, Paxinos G (eds) The human nervous system. Academis Press, Amsterdam, pp 759-834

Young MP, Scannell JW, Burns GA, Blakemore C (1994) Analysis of connectivity: neural systems in the cerebral cortex. Rev Neurosci 5:227-250

Zhao G, Zhang Y, Ge Y, Zheng Y, Sun X, Zhang K (2018) Asymmetric hemisphere activation in tenderness: evidence from EEG signals. Sci Rep 8:8029

Zhao D, Wang Y, Li B (2020) Eye preference for emotional stimuli in Sichuan snub-nosed monkeys. Folia Primatol (basel) 91:630-642

Zhu Y, Gao H, Tong L, Li Z, Wang L, Zhang C, Yang Q, Yan B (2019) Emotion regulation of hippocampus using real-time fMRI neurofeedback in healthy human. Front Hum Neurosci 13:242

Publisher's Note Springer Nature remains neutral with regard to jurisdictional claims in published maps and institutional affiliations. 